\title{
KORELASI PRODUKSI SUSU DENGAN BCS SAPI FRIESIAN HOLSTEIN LAKTASI PERTAMA DI BBPTU-HPT BATURRADEN
}

\section{MILK PRODUCT CORRELATION WITH THE FIRST LACTATING FRESIAN HOLSTEIN COW BCS AT BBPTU-HPT BATURRADEN}

Wida Nurnaningsih $^{1 \mathrm{a}}$, T. Y. Astuti ${ }^{1}$, dan Y. Subagyo ${ }^{1}$

1 Jurusan Peternakan Fakultas Peternakan, Universitas Jenderal Soedirman Purwokerto Jl. DR. Soeparno No.60, Karangwangkal, Kec. Purwokerto Utara, Kabupaten Banyumas, Jawa Tengah 53122 aKorespondensi: Wida Nurnaningsih, E-mail: widanurnaningsi@gmail.com

(Diterima oleh Dewan Redaksi: 26-06-2020)

(Dipublikasikan oleh Dewan Redaksi: 30-04-2021)

\begin{abstract}
The purpose of this study was to determine the relationship between milk production of PFH dairy cows with BCS at the first lactation at BBPTU HPT Baturraden. The study was conducted from March 20 to April 20 2018, with research material consisting of 250 production data records and 250 BCS data records that were corrected in lactation months 1 to 10 originating from BBPTU HPT Baturraden. Data analysis shows that milk production has a close relationship with lactation month, the results are shown by the equation $y=-0.1223 x 2+0.6068 x+13.493$ with $\mathrm{R} 2$ of 0.97 . These results are reflected in the milk production curve which shows in the first month to the third month that there is an increase in milk production, with peak production being reached in the third month. Average peak milk production is 14.74 liters / head / day and average milk production Daily 12.12 liters / head / day. The results of the BCS analysis show that BCS has a close relationship with the lactation month, the results are shown by the equation $\mathrm{y}=2.9133+0.0132 \mathrm{x} 2+0.0365 \mathrm{x}$ shown with R2 of 0.95. The results on the BCS graph show that BCS is increasing as the lactation period progresses, the largest average BCS is obtained 3.79 in the 10th month. The relationship between milk production and BCS based on the analysis shows the equation $y=-3,9224 x 2+18,894 x-7,6087$, indicated by an R2 of 0.98 .
\end{abstract}

Keywords: PFH Dairy Cows, First Lactation, Milk Production, BCS, BBPTU HPT Baturraden.

\begin{abstract}
ABSTRAK
Tujuan dari penelitian ini yaitu mengetahui hubungan antara produksi susu sapi perah PFH dengan BCS pada laktasi pertama di BBPTU HPT Baturraden. Penelitian telah dilaksanakan pada tanggal 20 Maret sampai dengan 20 April 2018, dengan materi penelitian terdiri atas 250 catatan data produksi dan 250 catatan data BCS yang sudah terkoreksi pada bulan laktasi $1 \mathrm{~s} / \mathrm{d} 10$ yang berasal dari BBPTU HPT Baturraden. Analisis data menunjukan hasil bahwa produksi susu memiliki hubungan yang erat dengan bulan laktasi, hasil tersebut ditunjukan dengan persamaan $y=-0,1223 x^{2}+0,6068 x+13,493$ dengan $\mathrm{R}^{2}$ sebesar 0,97 . Hasil tersebut tergambar pada kurva produksi susu yang menunjukan pada bulan ke $1 \mathrm{~s} / \mathrm{d}$ bulan ke 3 terdapat kenaikan produksi susu, dengan puncak produksi tercapai pada bulan ke 3. Rataan produksi susu puncak sebesar 14,74 liter/ekor/hari dan rataan produksi susu harian 12,12 liter/ekor/hari. Hasil analisis BCS menunjukan bahwa BCS memiliki hubungan yang erat dengan bulan laktasi, hasil tersebut ditunjukan dengan persamaan $y=2,9133+0,0132 x^{2}$ $+0,0365 \mathrm{x}$ ditunjukan dengan $\mathrm{R}^{2}$ sebesar 0,95 . Hasil pada grafik BCS menunjukan bahwa BCS semakin meningkat seiring berjalan masa laktasi, rataan BCS terbesar diperoleh 3,79 pada bulan ke 10 . Hubungan Produksi susu dan BCS berdasarkan hasil analisis menunjukan persamaan $y=-3,9224 \mathrm{x}^{2}+$ 18,894x - 7,6087, ditunjukan dengan nilai $\mathrm{R}^{2}$ sebesar 0,98.

Kata kunci : Sapi PFH, laktasi pertama, Produksi susu, BCS, BBPTU HPT Baturraden.

Wida Nurnaningsih, T. Y. Astuti, Y. Subagyo. 2012. Kolerasi Produksi Susu Dengan BCS Sapi Friesian Holstein Laktasi Petama Di BBPTU-HPT BATURRADEN. Jurnal Peternakan Nusantara 7(1): 19-24
\end{abstract}




\section{PENDAHULUAN}

Sapi FH merupakan salah satu bangsa sapi perah yang memiliki produksi susu tertinggi, di negara asalnya Belanda produksi susu sapi FH dapat mencapai 6000 s/d 8000 liter/ekor/laktasi, sayangnya produksi susu optimal sapi FH di Indonesia hanya berkisar 3000 s/d 4000 liter/ekor/laktasi yang artinya hanya dapat mencapai setengah dari produksi susu di negara asalnya ( Novianti et al,.2013). Hasil tersebut dapat dipengaruhi oleh berbagai faktor antara lain, perbedaan iklim, pakan, penyakit, dan manajemen perawatan.

Balai Besar Pembibitan Ternak Unggul dan Hijauan Pakan Ternak (BBPTU HPT Baturraden) merupakan salah satu balai yang dimiliki oleh pemerintah yang bertujuan untuk menghasilkan bibit unggul sapi perah. Lokasi BBPTU HPT Baturaden yang berada di lereng Gunung Slamet memiliki temperatur yang relatif rendah yaitu $18 \mathrm{~s} / \mathrm{d} 28^{\circ} \mathrm{C}$ dengan kelembaban $80 \%$ sehingga sapi $\mathrm{FH}$ diharapkan dapat beradaptasi dengan baik dan menghasilkan produktivitas yang baik. Sapi perah yang memasuki masa laktasi harus diperhatikan kecukupan kebutuhan konsumsi pakannya, hal tersebut berkaitan dengan energi yang dibutuhkan untuk hidup pokok, produksi susu dan reproduksi. Pakan yang tidak mencukupi pada ternak yang sedang berproduksi berakibat pada mobilisasi cadangan energi tubuh, sehingga terjadi penurunan produksi, bobot badan, BCS dan bila semakin parah mengakibatkan ternak ambruk.

Penanganan yang dibutuhkan untuk mencegah terjadinya kondisi tersebut adalah dengan mengetahui secara dini kondisi ternak salah satunya dengan metode penilaian BCS yang bertujuan untuk mengetahui kondisi ternak melalui visualisasi dan perabaan pada tubuh ternak. BCS ideal untuk sapi perah yaitu 3 , apabila kurang dari 3 tandanya ternak mengalami mobilisasi energi dalam tubuh sehingga berakibat pada menurunnya produksi, $\mathrm{S} / \mathrm{C}$, dan jarak beranak yang panjang. Oleh karena itu perlu dilakukan penelitian tentang "Hubungan antara Produksi Susu dengan Body condition Score (BCS) Sapi Perah Friesian Holstein (FH).

\section{MATERI DAN METODE}

Hasil penelitian memperoleh data sebagai berikut, data produksi susu sebanyak 250 , dan data BCS sebanyak 250. Data yang diperoleh kemudian disajikan dalam Tabel tabulasi data yang kemudian dianalisis menggunakan regresi non linier kuadrater, hasil yang diperoleh berupa kurva laktasi dan grafik BCS. Pelaksanaan penelitian menggunakan metode purposive random sampling dengan pengambilan data berdasarkan data Produksi susu dan BCS terkoreksi pada laktas pertama. Data yang digunakan merupaka catatan pada bulan Januari 2016 sampai dengan bulan Februari 2018, bertempat di BBPTU HPT Baturraden dengan jumlah ternak sebanyak 25 ekor sapi FH.

Data yang tersaji di dalam tabulasi data kemudian diuji menggunakan rumus regresi non linier kuadrater, sehingga diperoleh kurva laktasi dan grafik BCS serta hubunga antara produksi susu dan grafik BCS. Persamaan rumur berdasarkan Steel and Torrie (1980), aadalah sebagai berikut :

$$
Y=\beta 0+\beta 1 X+\beta 2 X^{2}
$$

\section{HASIL DAN PEMBAHASAN}

Produksi Susu Sapi FH Laktasi Pertama

Data rataan produksi susu sapi $\mathrm{FH}$ pada laktasi pertama di BBPTU HPT Baturraden dimulai pada bulan ke 1 sampai dengan bulan ke 10 disajikan pada Tabel 1.

Tabel 1. Rataan Produksi Susu Sapi Perah FH Laktasi Pertama

\begin{tabular}{ccc}
\hline $\begin{array}{l}\text { Bulan } \\
\text { Laktasi }\end{array}$ & $\begin{array}{l}\text { Rataan 3 } \\
\text { Semester }\end{array}$ & Produksi Susu (L) \\
\hline 1 & & 13,61 \\
2 & 14,15 & 14,11 \\
3 & & 14,74 \\
4 & & 14,59 \\
5 & 13,46 & 13,47 \\
6 & & 12,32 \\
7 & & 11,1 \\
8 & & 10,61 \\
9 & & 9,15 \\
10 & 12,79 & 7,51 \\
\hline Rataan & & 12,12 \\
\hline
\end{tabular}

Tabel di atas menunjukan produksi susu sapi FH laktasi pertama memiliki rataan 12,12 liter/laktasi, data tersebut menujukan bahwa rataan produksi susu di BBPTU HPT Baturraden masih lebih rendah dibandingkan rataan produksi susu Nasional sebesar 13,11 liter/laktasi/tahun (BPS,2015). Kondisi tersebut 
dapat dipengaruhi oleh berbagai faktor seperti, temperatur, pakan dan manajemen.

Temperatur lingkungan di Baturraden 18$28^{\circ} \mathrm{C}$, dengan kelembaban $70-80 \%$, Yani dan Purnomo (2006), bahwa sapi FH berasal dari negara Eropa beiklim sedang dengan tempratur $13-25^{\circ} \mathrm{C}$ dengan kelembapan udara $80 \%$ sapi $\mathrm{FH}$ yang rentan terhadap perubahan tempratur produksi susu nya akan terus menurun apabila mendapatkan cekaman panas. Hal tersebut mengakibatkan sapi FH di BBPTU-HPT Baturraden tidak dapat berproduksi secara optimal, dibandingkan dengan produksi di daerah asalnya, Faktor lain yang dapat berpengaruh terhadap produksi yaitu pakan.

Lingkungan BBPTU HPT Baturraden memiliki tempratur $18 \mathrm{~s} / \mathrm{d} \quad 28^{\circ} \mathrm{C}$, dengan kelembapan $70 \mathrm{~s} / \mathrm{d} 80 \%$. Faktor tersebut tentu berpengaruh terhadap produksi susu sapi FH di BBPTU HPT Baturraden, selain itu faktor pakan juga menentukan produksi susu yang dihasilkan. Pakan sapi FH di BBPTU HPT Baturraden menggunakan metode Total Mix Ration (TMR), terdiri atas rumput, jerami, pacing dan legum dicampur menjadi satu dengan konsentrat. Pakan yang diberikan berupa hijauan sebanyak $73 \mathrm{Kg} /$ ekor/hari dan konsentrat 9,57 Kg/ekor/hari, pemberian tersebut berdasarkan pada kebutuhan hijauan $60 \%$ dari BB untuk konsentrat $40 \%$ dari BB (Siregar, 2001).

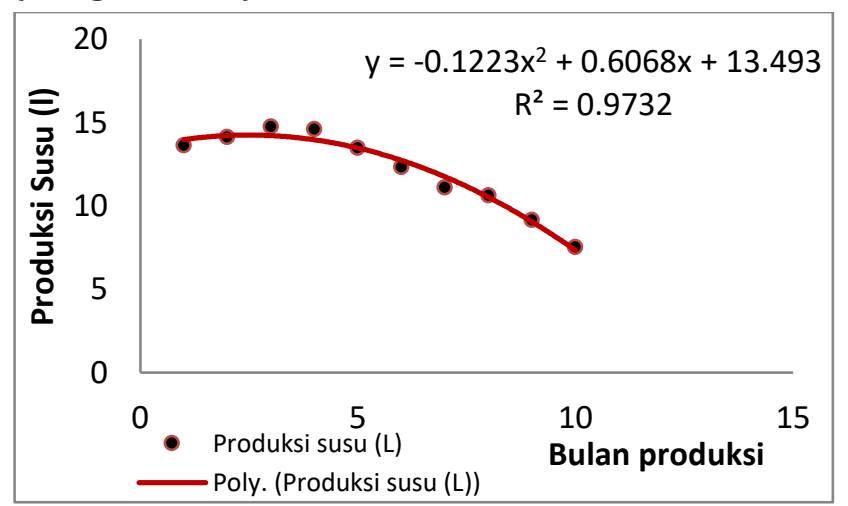

Gambar 1. Grafik Produksi Susu Sapi FH Laktasi Pertama

Hasil grafik pada gambar 1 menunjukan produksi susu sapi FH laktasi pertama sesuai dengan garis prediksi produksi, hanya pada bulan ke 3 dan 4 produksi menunjukan titik maksimum melampaui garis prediksi, dan pada bulan ke 6 dan 7 penurunan produksi susu sedikit berada dibawah garis prediksi. Atabany et al., (2008) menjelaskan bahwa puncak produki susu sapi FH laktasi pertama tercapai pada bulan ke 4, dan pada laktasi kedua menjadi lebih cepat yaitu pada bulan ke 3. Analisi data menunjukan hasil bahwa nilai signifikan antara produksi susu dan bulan laktasi sebesar $0,00<0,05$ artinya bulan laktasi berpengaruh nyata terhadap produksi susu. Nilai $\mathrm{R}^{2}=0,97$ berarti bulan laktasi berpengaruh sebesar 0,97 terhadap produksi susu. Hasil tersebut sesuai dengan Siregar (1993), bahwa lama laktasi berpengaruh terhadap produksi susu, peningkatan produksi akan tercapai setelah 3035 hari dan selanjutnya akan menurun sampai memasuki masa kering.

Data produksi susu menunjukan bahwa pada bulan ke 1 rataan produksi susu 13,61 liter, meningkat 0,5 liter pada bulan ke 2 14,11 liter, puncak produksi tercapai pada bulan ke 3 sebesar 14,74 liter dengan kenaikan 0,63 liter. Puncak produksi sapi FH tercapai pada minggu ke 8, sementara berdasarkan hasil puncak produksi tercapai pada bulan ke 3 , terlambatnya tercapainya puncak produksi dapat dipengaruhi faktor genetik, lingkungan, pakan dan manajemen pemeliharaan. Produksi susu pada bulan ke 4 mulai mengalami penurunan sebesar 0,15 liter, hingga akhir produksi pada bulan ke 10 produksi susu sebesar 1,64 liter. Produksi susu akan mengalami penurunan setelah tercapainya puncak produksi, prosentase penurunan produksi susu ideal yaitu : 13\%, $13 \%, 12 \%, 12 \%, 10 \%, 10 \%, 9 \%, 8 \%, 7 \%, 6 \%$ (Prihardi dan Adiarto, 2010).

\section{Body Condition Score (BCS) Sapi FH Laktasi Pertama}

Hasil rataan BCS menunjuka peningkatan dan penurunan BCS tidak terlalu signifikan, namun hasil tersebut masih menunjukan nilai BCS ideal data tersebut tersaji pada Tabel 2.

Tabel 2. Rataan BCS Sapi FH Laktasi Pertama di BBPTU-HPT Baturraden

\begin{tabular}{ccc}
\hline $\begin{array}{c}\text { Bulan } \\
\text { Laktasi }\end{array}$ & $\begin{array}{c}\text { Rataan 3 } \\
\text { Semester }\end{array}$ & BCS \\
\hline 1 & & 3,02 \\
2 & 2,89 & 2,8 \\
3 & & 2,85 \\
4 & & 2,93 \\
5 & 3,06 & 3 \\
6 & & 3,25 \\
7 & & 3,38 \\
8 & & 3,52 \\
9 & 3,59 & 3,66 \\
10 & & 3,79 \\
\hline Rataan & & 3,22 \\
\hline
\end{tabular}


Nilai BCS minimum berdasarkan data tersebut pada bulan ke 2 nilai BCS 2,8, terjadi peningkatan selama bulan laktasi, peningkatan BCS memasuki puncak pada bulan ke 10 dengan nilai 3,79. Analisis data menunjukan hasil yang signifikan antara BCS dengan bulan laktasi $0,00<0,05$ artinya bulan laktasi berpengaruh sangat nyata terhadap BCS, nilai $\mathrm{R}^{2}$ sebesar 0,95 menunjukan pengaruh bulan laktasi terhadap kenaikan BCS sebesar 0,95.

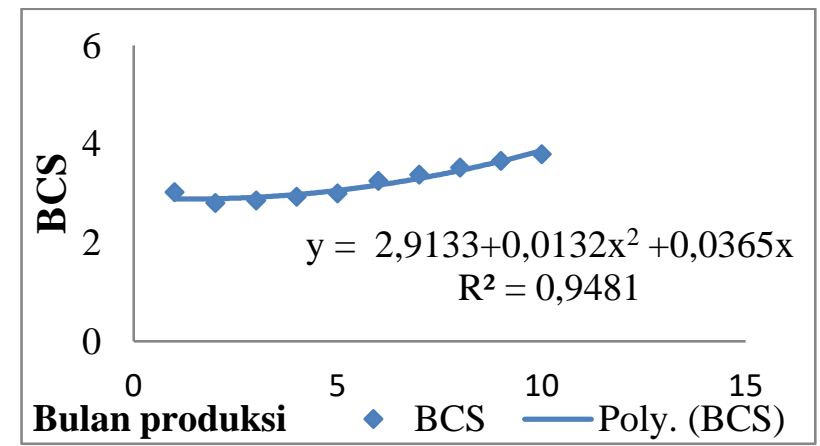

Gambar 2. Grafik BCS Sapi Perah FH Laktasi Pertama

Laktasi sapi $\mathrm{FH}$ terbagi menjadi tiga periode yaitu, periode awal (bulan ke 1,2,3), periode pertengahan (bulan ke 4,5,6) dan periode akhir (bulan 7,8,9,9, dan 10). Nilai BCS pada setiap periode tidaklah sama, hal tersebut dikarenakan kebutuhan energi ternak yang berbeda pada setiap periodenya. Pada masa akhir kebuntingan hingga tercapainya puncak laktasi nilai BCS perlu dijaga, karena pada akhir kebuntingan ternak membutuhkan cadangan energi yang besar hal tersebut berkaitan dengan kebutuhan pada awal kebuntingan. Ternak setelah partus akan mengalami penurunan feed intake oleh karena itu dibutuhkan cadangan energi yang cukup agar mobilisasi cadangan lemak tubuh tidak terlalu besar sehingga tidak berdampak pada kondisi tubuh ternak. Data hasil penelitian menunjukan BCS sapi pada awal laktasi terus mengalami penurunan dari bulan ke 1 sebesar 3,02 sampai pada bulan ke 3 menurun menjadi 2,85. Sapi perah akan mengalami penurunan BCS sebesar 0,50 s/d 1,00 setelh 60 hari partus (Ensiminger dan Tyler,1978).
BCS ideal sapi perah sangat penting untuk dijaga karena akan berpengaruh terhadap tercapainya puncak produksi, nilai BCS awal laktasi yang ideal 3. Nilai BCS menunjukan adanya kenaikan pada periode pertengahan atau setelah melewati masa puncak dengan BCS sebesar 3,25. Nilai BCS yang meningkat setelah melewati periode puncak latasi dapat diakibatkan beberapa faktor antara lain, feed intake yang meningkat, persiapan untuk tumbuh fetus atau masa kebuntingan (Sukandar, 2008). Laktasi pada perode terakhir mencapai nilai tertinggi sebesar 3,79, menurut Sukandar (2008), nilai minimal BCS 2,00 dan maksimal 3,75 artinya nilai BCS sapi FH di BBPTU HPT melebihi kriteria ideal. Periode akhir laktasi nilai BCS akan mengalami peningkatan dikarenakan adanya pertumbuhan fetus dan persiapan periode berikutnya, namun keseimbangan energi tubuh tetap harus dijaga agar mobilisasi energi pada cadangan lemak tubuh tidak terlalu berlebih (Taufik et al., 2013).

Hubungan antara Produksi Susu dengan BCS Sapi FH Laktasi Pertama Kurva dibawah ini menunjukan hubungan antara produksi susu dengan BCS pada sapi FH laktasi pertama di BBPTU HPT Baturraden.

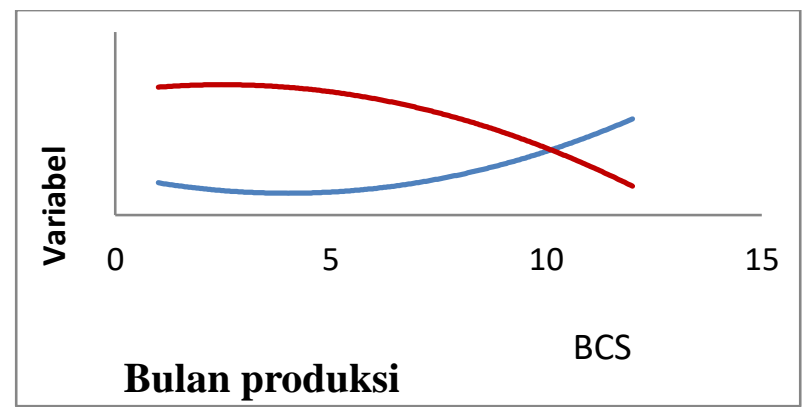

Gambar 3. Grafik BCS dengan Produksi Susu Sapi Perah FH Laktasi Pertama

Kurva yang ditunjukan pada Gambar 3 menunjukan bahwa terhadap hubungan yang erat antara Produksi susu dengan BCS pada laktasi pertama, terlihat adanya penurunan BCS pada saat terjadi peningkatan produksi susu. Penurunan produksi susu berbanding terbalik dengan peningkatan nilai BCS, pada akhir periode produksi susu mengalami penurunan sementara nilai BCS mencapai puncaknya. Data analisisi menunjukan persamaan sebagai berikut $y=-3,9224 x^{2}+18,894 x-7,6087$, nilai tersebut menunjukan hubungan antara 
produksi susu dengan BCS sangat erat ditunjukan dengan nilai signifikansi $0,00<0,05$, dengan koefisien determinan $\mathrm{R}^{2}=0,98$ artinya pengaruh BCS sebanyak 0,98.

Nilai BCS mengalami penurunan pada saat produksi susu meningkat, hal tersebut dikarenakan mobilisasi cadangan lemak tubuh yang berfungsi untuk memenuhi kebutuhan hidup pokok dan produksi susu. Sukandar (2008), menjelaskan bahwa setelah partus ternak mengalami ketidak seimbangan antara kesehatan dan feed intake atau Negtive Energi Balance (NEB). Puncak produksi tercapai pada bulan ke 3 sebesar 14,74 liter dengan nilai BCS 2,85, hal tersebut sesuai dengan Gallo et al., (1996) bahwa penurunan BCS akan terjadi pada bulan ke 2 atau 3 selanjutnya akan kembali meningkat. Sementara puncak nilai BCS tercapai pada bulan ke 10 sebesar 3,79 dengan produksi susu 7,51 liter.

\section{KESIMPULAN DAN IMPLIKASI}

Kesimpulan dari hasil penelitian menunjukan produksi susu memiliki hubungan erat dengan BCS, ditunjukan dengan nilai signifikansi $0,00<0,05$ dan $\mathrm{R}^{2} 0,98$.

\section{DAFTAR PUSTAKA}

Anggraeni, A., Y. Fitriani, A. Attabani, dan I. Komala. 2008. Penampilan Produksi Susu dan Reproduksi Sapi Perah Friesian Holstein di Balai Perbibitan Ternak Sapi Perah Cikole Lembang. Prosiding Seminar Nasional.

Atabany, A., B.P. Purwanto, T. Toharmat dan A. Anggraeni. 2008. Hubungan Masa Kosong dengan Produktivitas pada Sapi Perah Friesian Holstein di Baturraden, Indonesia. Media peternakan. 2011 :77-82.

Badan Pusat Stastisik. 2015. Statistik Harga Konsumen Perdesaan Kelompok Makanan. Badan Pusat Statistik, Jakarta.

Ensminger, M. E., dan H. D. Tyler.1978. Dairy Cattle Science. Fourth Edition. Upper Saddle River, New Jersey.

Gallo L, Carnier P, Cassandro M, Mantovani R, Bailoni L, Bittante G. 1996. Change in Body

\author{
Condition Score of Holstein Cows as \\ Effected by Parity and Mature \\ Equivalment Milk Yield.J. Dairy Sci. 79 : \\ 1.0091 .015$.
}

Novianti, J., B.P. Purwanto., Novianti. 2013. Respon Fisiologis dan Produksi Susu Sapi Perah FH pada Pemberian Rumput Gajah (Pennisetum Purpureum) dengan Ukuran Pemotongan yang Berbeda. Jurnal Ilmu Produksidan Teknologi Peternakan 1 (3): 138-146.

Prihadi, S dan Adiarto. 2008. Ilmu Ternak Perah. Fakultas Peternakan UGM:Yogyakarta

Siregar, S. B. 2001. Peningkatan Kemampuan Berproduksi Susu Sapi Perah Laktasi Melalui Perbaikan Pakan dan Frekuensi Pemberiannya. Jurnal Ilmu Ternak dan Veteriner 6 (2): 76-82.

Siregar, S.B. 1993. Sapi Perah, Jenis, Teknik pemeliharaan dan Analisa Usaha. PT. Penebar Swadaya, Jakarta.

Sukandar, A., B.P. Purwanto Dan A. Anggraeni2. 2008. Keragaan BodyCondition Score dan Produksi Susu Sapi Perah Friesian-Holstein di PeternakanRakyat KPSBU Lembang, Bandung. Seminar Nasional Teknologi Peternakan dan Veteriner.

Taufik, R., Sarwiyono, Setyowati, E. 2013. Hubungan Body Condition Score (BCS) Terhadap Produksi dan Kualitas Susu pada Sapi Perah. Fakultas Peternakan. Universitas Brawijaya, Malang.

Yani, A dan Purwanto, B.P. 2006. Pengaruh Iklim Mikro Terhadap Respons Fisiologis Sapi Peranakan Fries Holland dan Modifikasi Lingkungan Untuk Meningkatkan Produktivitasnya (Ulasan). Media Peternakan 29(1) 
